\title{
La importancia de la geología en el estudio de los procesos de remoción en masa: el caso de Totomoxtla, Sierra Norte de Puebla, México
}

\author{
Lucia Capra ${ }^{1, *}$, José Lugo-Hubp², José Juan Zamorano-Orózco² \\ ${ }^{1}$ Centro de Geociencias, Universidad Nacional Autónoma de México, Campus Juriquilla, \\ Queretaro, Qro. 76230, México. \\ ${ }^{2}$ Instituto de Geografía, Universidad Nacional Autónoma de México, \\ Coyoacán, 04510 México D.F., México. \\ *1capra@geociencias.unam.mx
}

\begin{abstract}
Resumen
Cada año los procesos de remoción en masa afectan áreas densamente pobladas en todo el mundo. En México, durante la temporada de huracanes los relieves montañosos son afectados por distintos procesos de remoción en masa, desde deslizamientos rotacionales a flujos de escombros. El evento hidro-metereológico que afectó la Sierra Norte de Puebla a principios del mes de octubre de 1999 ha generado miles de procesos de remoción en masa. Los deslizamientos de mayor magnitud han sido disparados en laderas inestables debido a la presencia de debilidades de tipo geológico-estructural, con la alternancia de horizontes de calizas y rocas deformadas formando flancos de grandes pliegues. El deslizamiento ocurrido en el poblado de Totomoxtla es un claro ejemplo de este tipo de inestabilidad, además con la peculiaridad de que, debido a la sobresaturación de agua de los horizontes metamórficos ricos en arcillas, la masa deslizante se transformó en un flujo de escombros cohesivo capaz de transportar por grandes distancias bloques de más de un metro de diámetro. Solamente con base en un estudio geológico-estructural detallado será posible generar mapas de susceptibilidad que puedan realmente evidenciar las zonas de posible afectación y así proponer la reubicación temporal de algunas viviendas durante la temporada de lluvias.
\end{abstract}

Palabras clave: Sierra Norte de Puebla, Totomoxtla, Zapotitlán de Méndez, deslizamientos, flujos de escombros cohesivos.

Abstract

Every year mass movement affect densely populated areas anywhere in the world. In Mexico, during the hurricane season mountain regions are affected by different mass movement processes such as rotational landslides and debris flows. The Sierra Norte de Puebla was affected by an intense hydro-meteorologic event at the beginning of October, 1999, which generated thousands of movements. The larger landslides were generated in unstable slopes due to the presence of geologic-structural, such as interbedded sequence of limestones and deformed rocks that constitute the limbs of large folds. The landslide happened in the town of Totomoxtla is a clear example of such instability, where the sliding mass transformed into a cohesive debris flow due to the water saturation of the clay-bearing 
metamorphic beds. This flow was able to transport blocks of more than a meter in diameter, up to great distances. Only with the aim of a detailed geologic-structural study it will be possible to generate susceptibility maps that can really demonstrate the threatened zones and thus propose the temporary relocation of some houses during the rain seasons.

Key words: Sierra Norte de Puebla, Totomoxtla, Zapotitlán de Méndez, landslide, cohesive debris flows.

\section{Introducción}

Cada año los procesos de remoción en masa afectan áreas densamente pobladas en todo el Mundo. En México, durante la temporada de huracanes, que va del mes de junio a finales del mes de octubre, los relieves montañosos, de origen volcánico o no, son afectados por distintos procesos de remoción en masa, desde deslizamientos rotacionales a flujos de escombros (Lugo-Hubp et al. 2001, 2005: Alcántara-Ayala, 2002; Alcántara-Ayala et al., 2006; Capra et al. 2003a; 2003b, Caballero et al., 2006). Las abundantes lluvias han sido el mecanismo disparador de estos fenómenos, originando casi simultáneamente cientos de movimientos, como ocurrió en Chiapas en octubre de 1998 durante la tormenta tropical Earl o en 1999 en la Sierra Norte de Puebla por la llegada de una depresión tropical. En la mayoría de los casos, las lluvias sobresaturaron los horizontes superficiales de suelo o rocas alteradas que fueron removilizadas fácilmente dando lugar a flujos de escombros, muchos de los cuales coincidieron con cortes de carretera o de áreas deforestadas. En la Sierra Norte de Puebla se tiene una situación geológica particular, con relieves constituidos por rocas plegadas del Paleozoico-Cretácico cubiertas por espesores de más de $10 \mathrm{~m}$, de depósitos volcánicos, ya pedogenizados en sus partes más superficiales. Ya de inicio, la geología de la región representa un factor relevante que limita la estabilidad del terreno, además de la deforestación y la ampliación o construcción de nuevas carreteras. Es de fundamental importancia considerar el factor geológico como una de las variables principales durante el análisis de estabilidad del terreno. En el presente trabajo, se aportan algunos ejemplos de cómo la estructura geológica y las características litológicas han producido diferentes tipos de procesos de remoción en masa, de distinta magnitud, alcance y movilidad, lo que representa diferentes tipos de amenaza. Todos los ejemplos que se reportan a continuación se refieren al evento catastrófico ocurrido en octubre de 1999 en la Sierra Norte de Puebla, en particular en su sector central, en los alrededores de los poblados de Zapotitlán de Méndez y Zacatlán (Figura 1).

\section{Descripción del evento}

A finales de Septiembre y durante la primera semana de octubre de 1999 la depresión tropical numero 11 ocasionó lluvias importantes en el noreste del país con picos máximos entre el 4 y el 5 de octubre. El efecto de las lluvias consistió en miles de procesos de remoción en masa en la ladera oriental de la Sierra Norte de Puebla (Lugo-Hubp et al., 2001). Los estados de Puebla, Tlaxcala y Veracruz fueron los más dañados con un total de 200,000 personas afectadas y 384 muertos. Los daños económicos fueron masivos, solo para el estado de Puebla se estimó en 200 millones de dólares (Vázquez-Conde et al., 2001). Un evento con características similares en la región ocurrió en los años cincuentas del siglo pasado (Lugo-Hubp et al., 20001). Sin embargo, durante la última década este tipo de fenómenos han ocurrido en cada temporada de lluvia causando daños mayores y muertes. El incremento en número y magnitud de estos eventos masivos disparados por lluvias abundantes puede ser explicado considerando el aumento

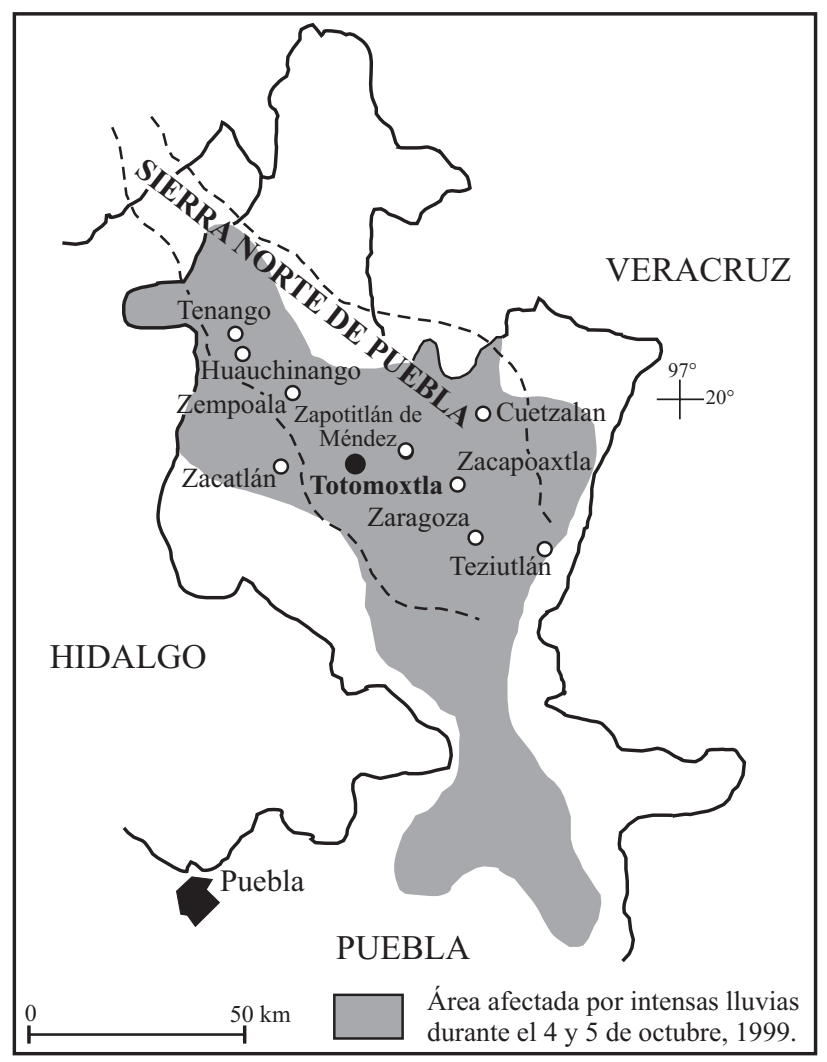

Figura 1. Ubicación del área de estudio. Localización de las zonas afectadas por las lluvias durante el evento de 1999 en la Sierra Norte de Puebla (Modificada de Lugo-Hubp et al., 2001). 

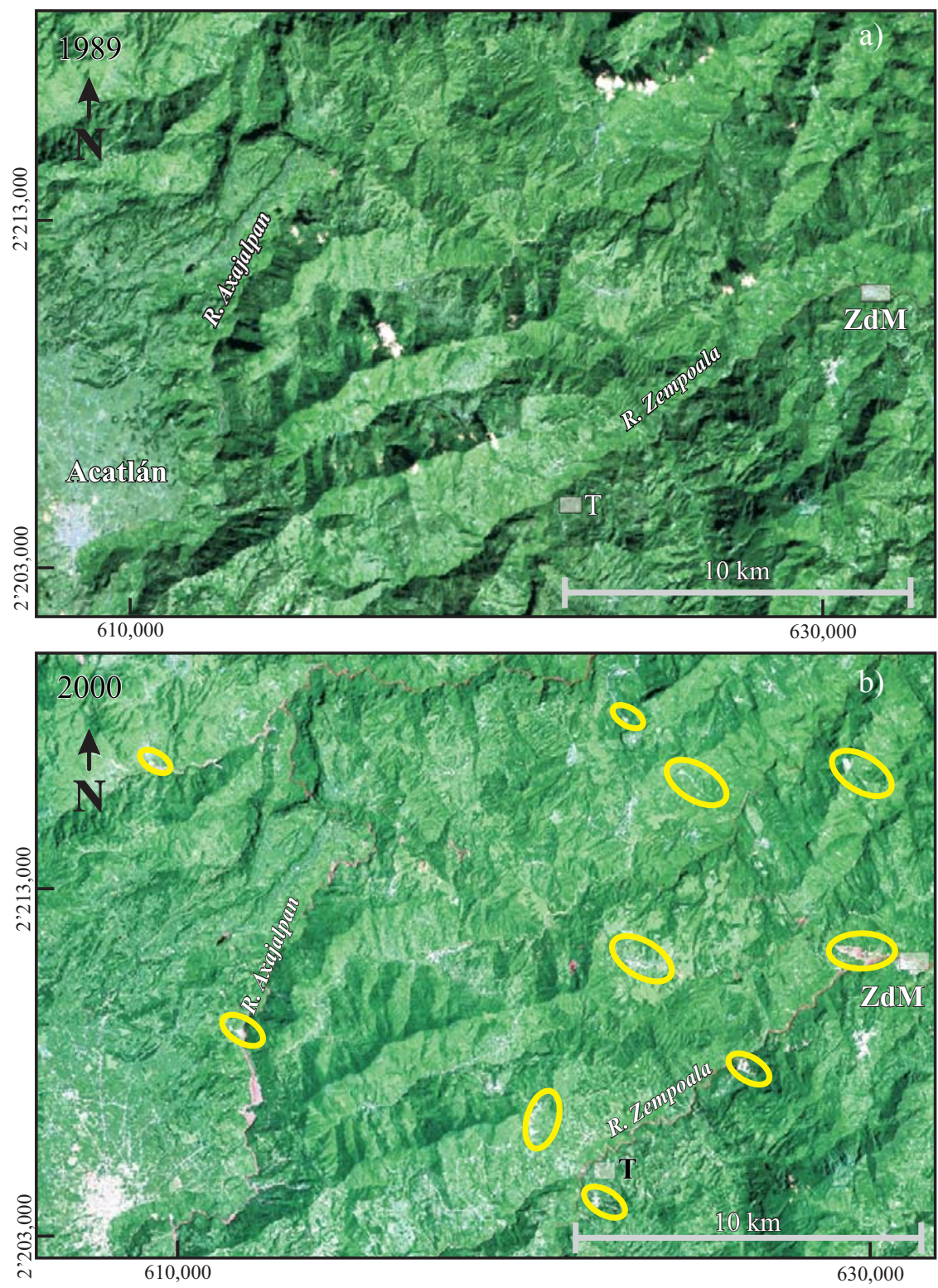

Figura 2. Comparación entre dos imágenes de satélite: a) imagen Landsat TM tomada en 1989, composición de las bandas 357 in RGB; b) imagen Landsat ETM tomada en 2000, composición de bandas 357 en RBG. Es muy evidente el cambio entre las dos imágenes por efecto de los procesos de remoción en masa ocurridos a principios de octubre de 1999. Los círculos en amarillo evidencian algunos de los procesos más importantes.

en la deforestación, la construcción de carreteras y otros tipos de obras antrópicas que no tienen la debida planeación (Alcántara-Ayala et al., 2006). Por estos motivos, es muy importante determinar cuales son los factores geológicoestructurales que debilitan una ladera para poder generar mapas de susceptibilidad para deslizamientos que podrían ser desencadenados por lluvias abundantes.

En la Figura 2 se presenta una comparación entre dos imágenes de satélite, una adquirida en 1989 (TM, bandas 3,5 y 7 en compuesto RGB) y otra en 2000 (ETM, bandas 3,5 y 7 en compuesto RGB). Es muy notable que en la imagen de 1989 aparecen todas las laderas cubiertas por abundante vegetación por lo que las trazas de los ríos se pueden intuir solamente en las partes más bajas de las cañadas. Por el contrario, en la imagen de 2000, adquirida casi seis meses después del evento de Puebla, muestra claramente los rasgos dejados por los numerosos deslizamientos, con ríos que muestran un caudal mucho mayor con respecto a la imagen anterior. Por ejemplo, en el Rió Axajalpán se pueden observar los límites de inundación para una creciente excepcional (Figura 2). Esto se debe a que todo el material removido de las laderas se acumuló en los drenajes, en algunos de los casos formando pequeños represamientos naturales, destruidos por la corriente de agua rápida, y en otros casos aumentando el volumen de material en suspensión en los ríos. 


\section{Marco geomorfológico y geológico}

El área de estudio se localiza en la ladera superior de la Sierra Norte de Puebla, y más en particular en el sector meridional, constituido por rocas plegadas jurásicas y cretácicas (Lugo-Hubp et al., 2005). Esta región presenta la mayor densidad de cauces fluviales así como los cortes de disección más profundos que alcanzan entre 300 y 800 metros (Lugo-Hubp et al., 2005). La energía elevada del relieve que caracteriza a este sector se puede explicar considerando su mayor altitud con respecto a las otras áreas del la Sierra Norte de Puebla. La Figura 3 ilustra de manera esquemática la geología del área en donde se puede observar una secuencia constituida por conglomerados continentales intercalados con areniscas y limonitas (Jurásico Medio) cubiertos por una secuencia marina de calizas alternadas con margas, lutitas y areniscas (Formación Tamán, Jurásico Superior), que cambia a una secuencia de borde de plataforma con calizas (Formación Pimienta, Jurásico Superior) y de cuenca (Cretácico, Formación Tamaulipas). Todas estas rocas sufrieron la fase de deformación Laramídica durante el Cretácico Superior-Paleoceno, formando pliegues cuyos ejes principales tienen orientación NO-SE. Finalmente el volcanismo Terciario ha cubierto parcialmente estas rocas con depósitos piroclásticos (INEGI, 1984; López-Reyes et al., 1997).

\section{Análisis espacial y tipo de movimientos}

La Figura 4 presenta el resultado del procesamiento de la imagen de satélite adquirida en el mes de abril de 2000 (Landsat ETM, $30 \mathrm{~m}$ de resolución), prácticamente seis meses después de la ocurrencia del evento. A la imagen se le aplicó un análisis de componentes principales para poder resaltar en las primeras bandas la mayor cantidad de información. La imagen que se muestra en la figura 4 es una representación en RGB de las primeras tres componentes. Todas las áreas que resaltan en color rojo representan zonas con humedad elevada, incluyendo los
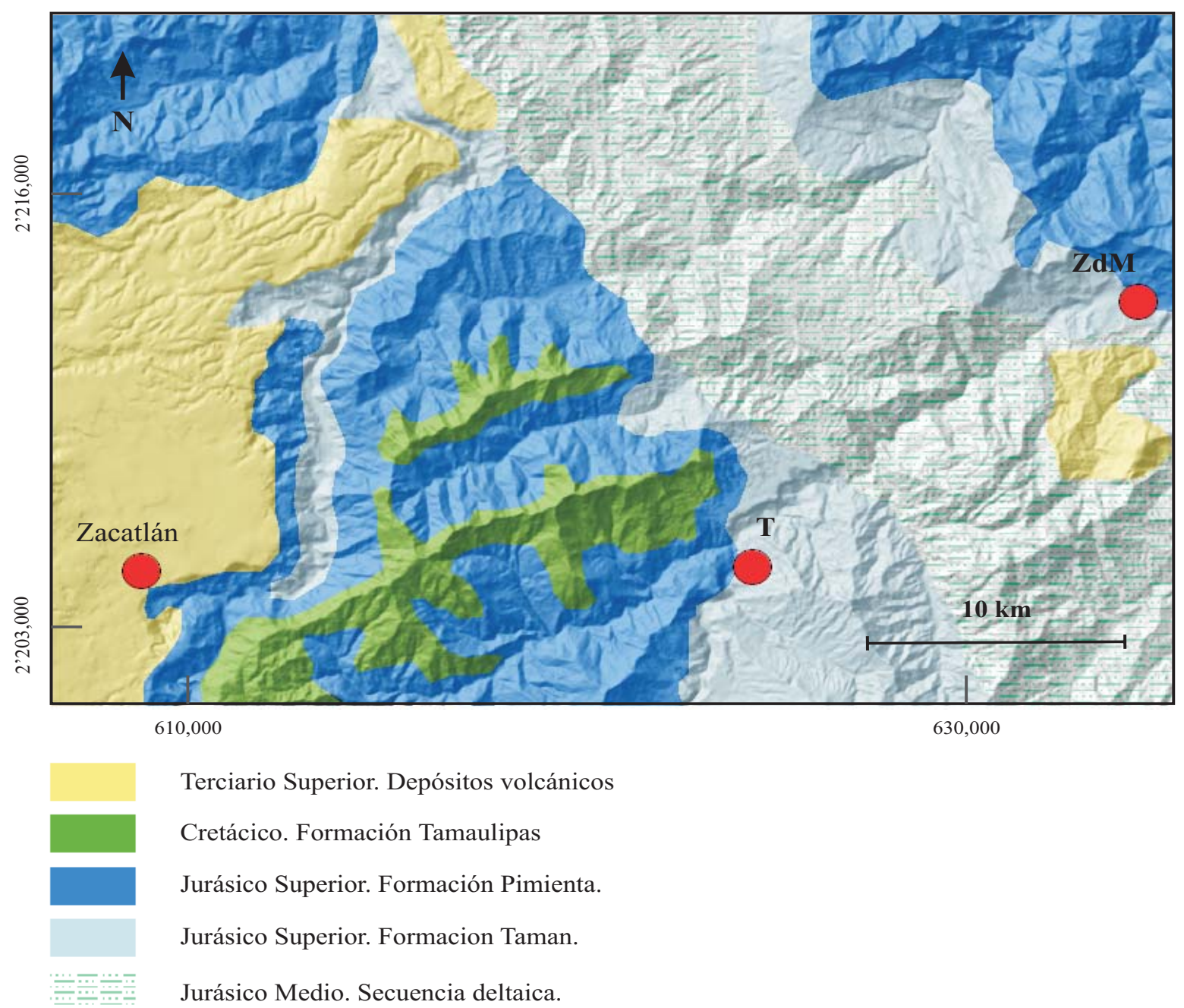

Figura 3. Mapa geológico simplificado del área de estudio. 
ríos y las áreas afectadas por algún proceso de remoción en masa. La mayoría de estos movimientos se localizan en las zonas cóncavas de las laderas (Figura 5a) y en muchos casos se inician al borde de las carreteras o en el límite de barrancos donde la mayoría de los poblados se han establecido (Figura 5b). Este es un problema recurrente ya que debido a la elevada disección de la Sierra, las partes planas están bordeadas por barrancos profundos en los límites de los cuales se han asentados poblaciones (Figura 5b). Entre los miles de movimientos registrados durante el evento de 1999, se han descritos distintos mecanismos, desde deslizamientos rotacionales en rocas, suelo, caída de bloques y flujos de escombros (Figura $5 \mathrm{c} \mathrm{y} \mathrm{d).} \mathrm{La} \mathrm{distribución} \mathrm{y} \mathrm{características} \mathrm{de} \mathrm{todos}$ estos movimientos no son casuales. En particular, se ha observado que la alternancia de litologías con diferente competencia y permeabilidad representan un factor clave en la inestabilidad de una ladera. Si a esto agregamos
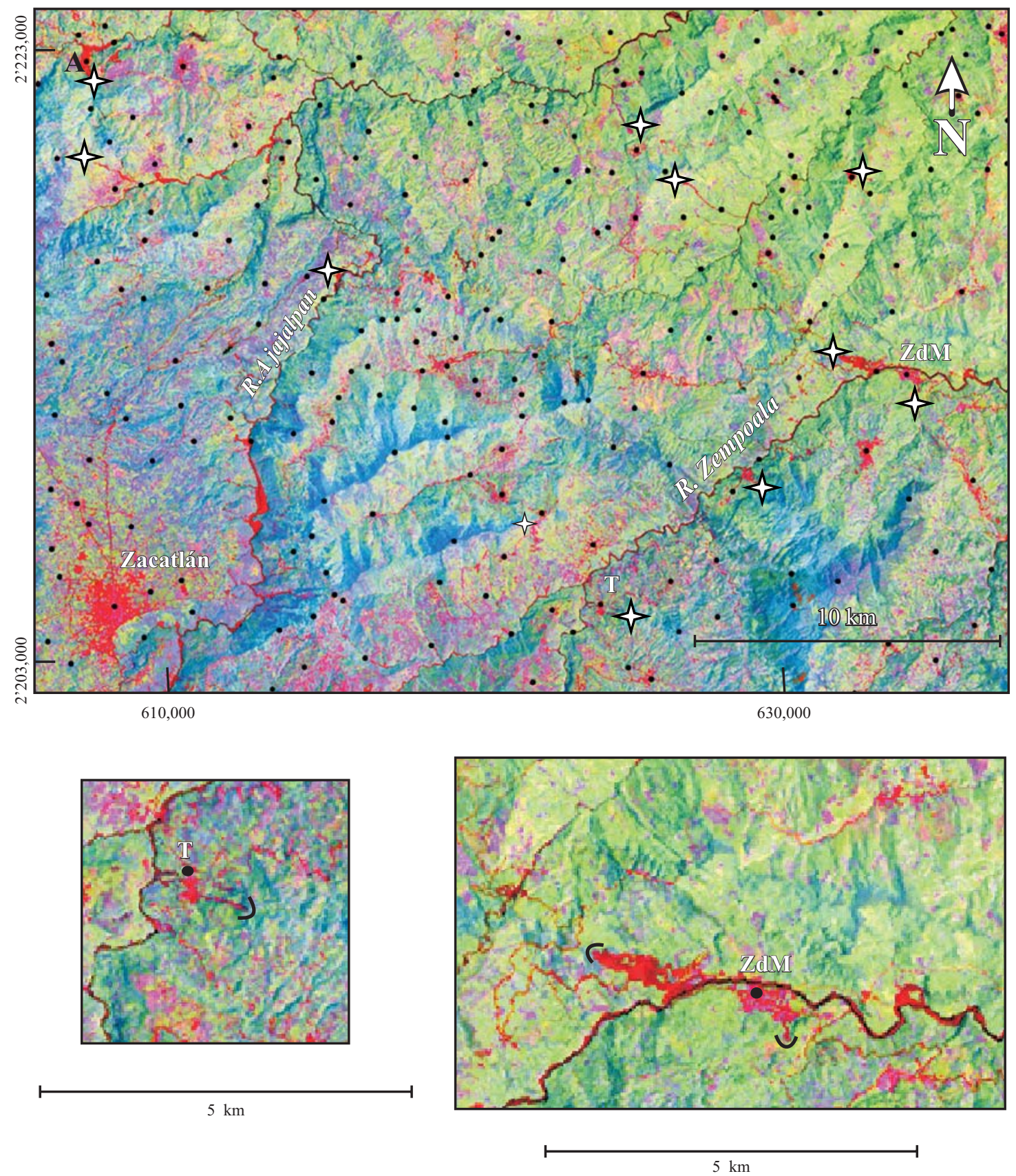

Figura 4. Imagen compuesta en RGB de las primeras tres componentes principales obtenidas a partir del procesamiento de la imagen Landsat ETM del 2000. Las estrellas blancas indican los puntos en donde se verificaron los procesos de remoción en masa de mayor magnitud, entre los cuales se distinguen los de Zapotitlán de Méndez (ZdM), de Acalama (A) y de Totomoxtla (T). Los círculos negros representan los pueblos de la región. Los acercamientos de la imagen se refieren a los deslizamientos de Zapotitlán de Méndez y de Totomoxtla. 

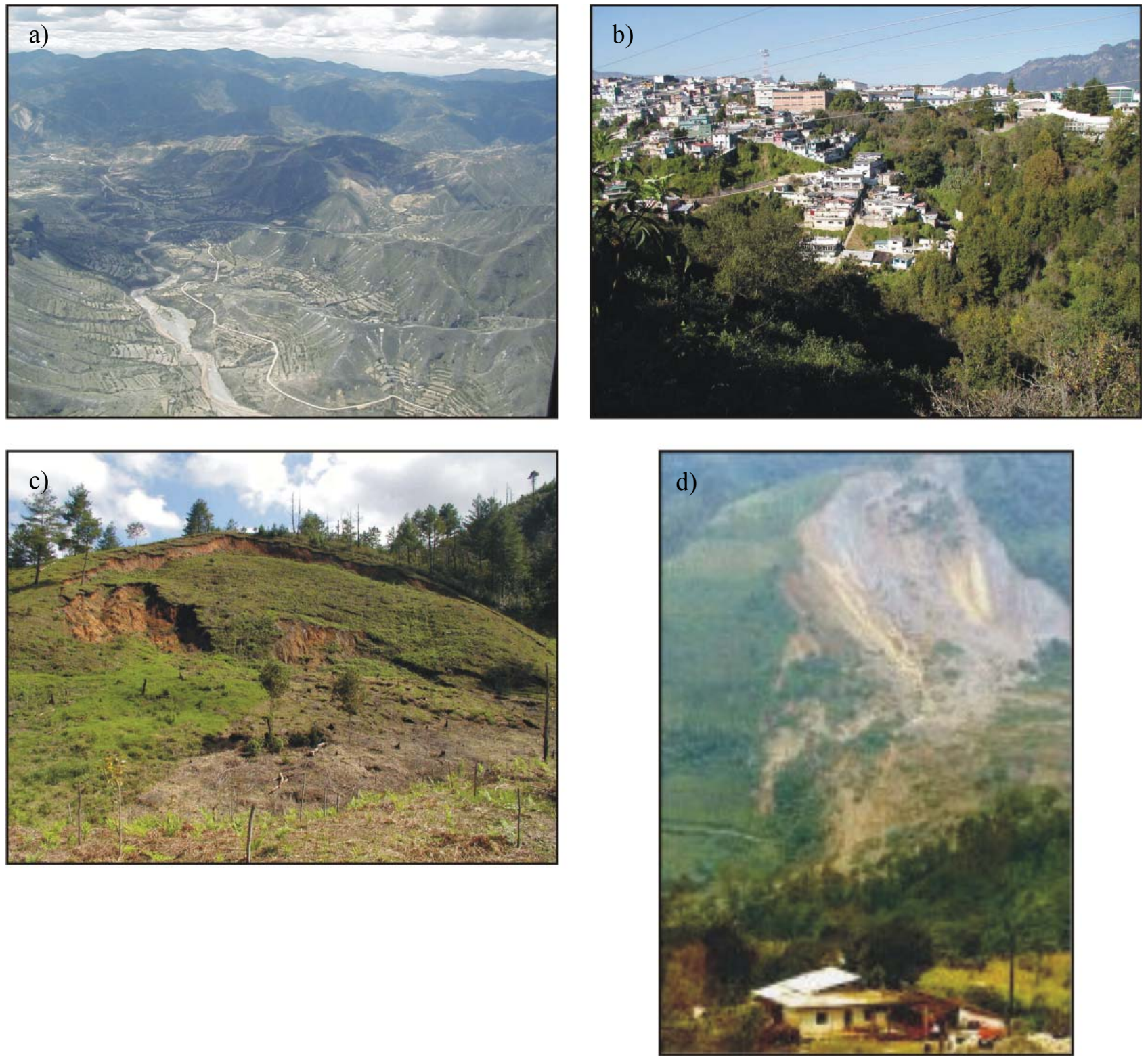

Figura 5. Ejemplos de procesos de remoción en masa ocurrido en 1999. a) Vista aérea de una porción de la Sierra Norte de Puebla en donde se aprecian decenas de flujos de escombros originados en las porciones cóncavas del relieve. b) Ejemplo de cómo aumentan las estructuras antrópicas en los poblados; la foto se refiere al poblado de Teziutlán. c) Ejemplo de deslizamiento en suelos y rocas del paleozóico. d) El deslizamiento de Acalama en donde se puede observar el desgarre del cerro que provocó severos daños al poblado.

que la geometría de los horizontes geológicos es tal que las superficies de discontinuidad (ya sea hidráulica o litológica) interceptan la superficie topográfica, el movimiento será todavía más probable. Estas condiciones son muy comunes en la Sierra Norte de Puebla, en donde se han descrito muchos ejemplos, tanto en rocas y suelos volcánicos como en rocas sedimentarias. En el primer caso, en una secuencia volcánica es muy común encontrar la alternancia de depósitos incoherentes y con diferente porosidad intercalados con paleosuelos muy ricos en arcilla, lo que origina discontinuidades lito-hidrológicas que coinciden con las superficies de movimiento (Figura 6a). Los eventos ocurridos en el poblado de Teziutlán, en donde se tuvo el mayor número de muertes, se debieron a la presencia de paleosuelos ricos en arcillas cubiertos por depósitos de caída de pómez altamente permeables, aunado a la presencia de una barda de concreto que favoreció la infiltración y acumulación del agua (Lugo-Hubp et al., 2001; Capra et al., 2003a). En el segundo caso, debido a la estructura particular de la Sierra Norte de Puebla, constituida por capas sedimentarias deformadas, es muy común observar en los cortes de carreteras horizontes de calizas compactas intercaladas con esquistos, formando los flancos de pliegues que buzan a favor de la pendiente. 
Esta estructura particular favorece la infiltración de agua y su acumulación en los estratos constituidos por esquistos enriquecidos en material cloritizado, con abundante arcilla (Figura 6b). Los deslizamientos ocurridos en la cercanía del pueblo de Zapotitlán de Méndez fueron descritos como movimientos mixtos, iniciados como deslizamientos rotacionales en calizas y esquistos y transformados en flujos de escombros por el agua abundante presente en la masa deslizante (Capra et al., 2003b). En algunos casos también se observaron ignimbritas soldadas involucradas en este tipo de deslizamientos (Figura 6b). El deslizamiento ocurrido en el poblado de Totomoxtla presenta estas características, sin embargo es muy peculiar debido al tipo de flujo de escombros originado, que fue descrito por los testigos como un flujo muy lento, lo que permitió que la gente se alejara de sus viviendas.
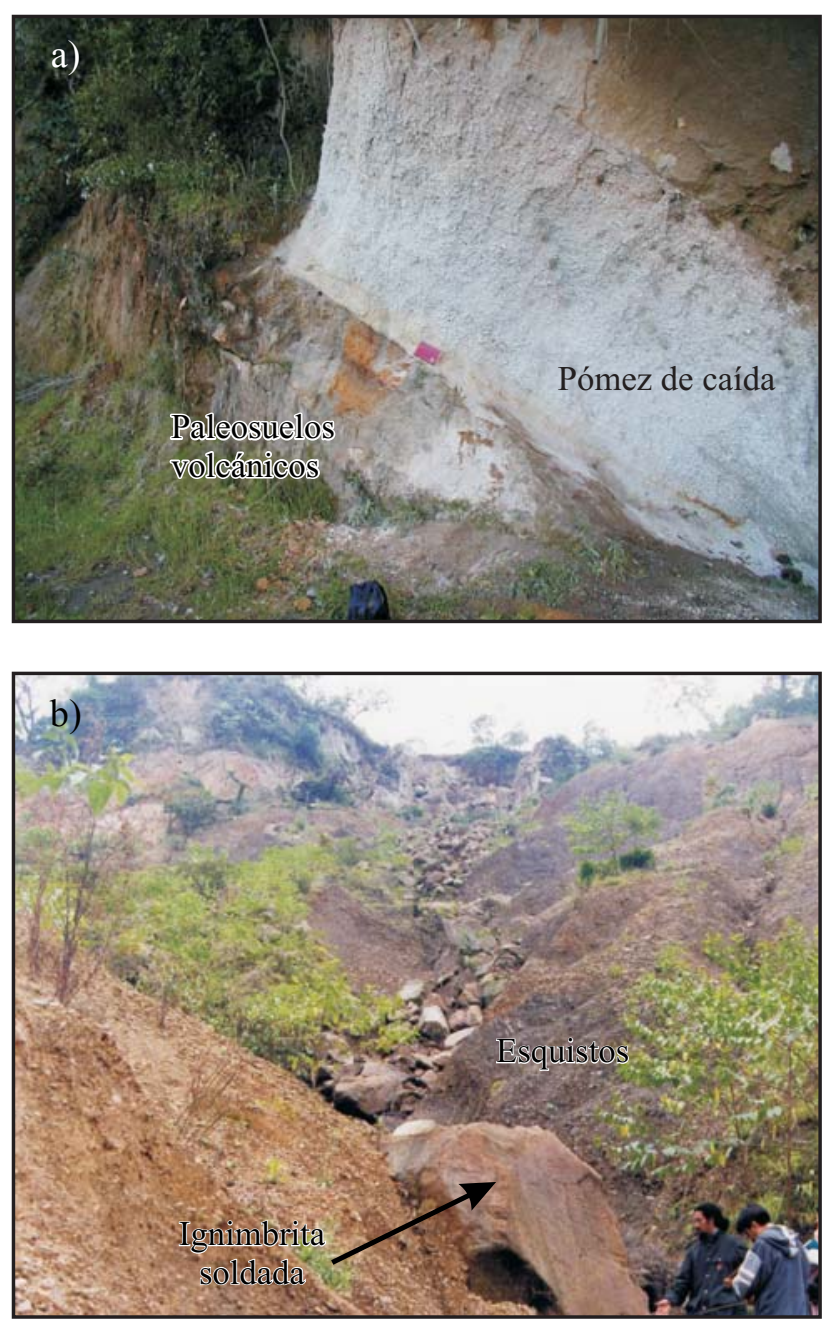

Figura 6. a) Sección estratigráfica realizada cerca del poblado de Teziutlán en donde se muestra un depósito de caída de pómez sobre a una serie de paelosuelos de origen volcánico muy arcillosos. b) Vista general del deslizamiento ocurrido en la localidad El Salto en el Poblado de Zapotitlán de Méndez en donde se observa a las lutitas foliadas en las cuales se originó la superficie de deslizamiento y a los bloques coherentes de ignimbrita soldada transportados por el flujo de escombros.

\section{Fenómenos de remoción en masa en Totomoxtla}

El poblado de Totomoxtla está ubicado en la margen izquierda del Río Zempoala, a una altitud de $1260 \mathrm{~m} \mathrm{snm}$ (Figura 1). Los relieves que rodean la zona están formados por una secuencia carbonatada del Jurásico constituida por calizas con espesor variable de hasta $50 \mathrm{~m}$ que cubren a una alternancia de capas de lutitas y areniscas deformadas con un grado de metamorfismo bajo (pizarras y filitas cloritizadas). En particular, en la ladera SE donde se localiza el poblado, los estratos que conforman a la secuencia deformada buzan a favor de la pendiente con una inclinación de hasta $65^{\circ}$ con un intenso clivaje. Como se puede apreciar de la fotografía de la Figura 7, las capas superiores (calizas) están inclinadas en dirección de la pendiente. Estas capas descansan sobre las filitas y pizarras deformadas que se observan en los escarpes formados por el deslizamiento. El evento ocurrido en 1999 fue causado por la sobresaturación de estos horizontes metamórficos los cuales sirvieron de superficie de deslizamiento para las capas de calizas que se fracturaron en bloques grandes durante el transporte (Figura 8). Según la clasificación propuesta por Hoek et al. (1998), en donde se define el índice de calidad geomecánica para macizos rocoso, las filitas y pizarras podrían corresponder con la categoría de rocas "muy foliada" (macizo rocoso plegado, altamente fracturado, constituido únicamente por rocas muy foliadas) que corresponde a un intervalo de GSI (Geological Strength Index) entre 5 y 30. Para un GSI entre 30 y 5 , la roca tiene un ángulo de fricción entre $25^{\circ}$ y $3^{\circ}$ y el fallamiento gravitacional ocurre a lo largo de una superficie de debilidad que normalmente corresponde con las superficies del mismo clivaje. En el caso aquí analizado, el movimiento inició como un deslizamiento translacional y se transformó en un flujo de escombros que alcanzó el poblado de Totomoxtla, hasta inundar la cabecera municipal (Figura 7b). Esta trasformación lateral se debió a que las filitas y pizarras, saturadas con agua y abundante material arcilloso (cloritas), originaron una mezcla de fragmentos finos+arcilla capaz de transportar bloques métricos y coherentes de calizas por grandes distancias (Figura $7 \mathrm{c} \mathrm{y} \mathrm{d}$ ).

Los análisis sedimentológicos llevados a cabo para el depósito de flujo de escombros indican claramente que se trata de un flujo cohesivo (se define cohesivo cuando la matriz contiene más del $3 \%$ de arcilla). En particular la matriz es extremadamente arcillosa ya que contiene hasta un $15 \%$ de arcilla (Figura 8). Además, el histograma granulométrico presenta una distribución bimodal con picos en $-3 \varphi$ y $7 \varphi$ lo cual está indicando la textura del depósito, con grandes bloques embebidos en una matriz muy fina, arcillosa (Figura 7c). Estas características sedimentológicas concuerdan con lo que los habitantes de Tomomoxtla cuentan sobre el evento. Ellos vieron un flujo de material que se desplazaba por la pendiente muy lentamente, y en donde los grandes bloques se movían hacia la superficie 

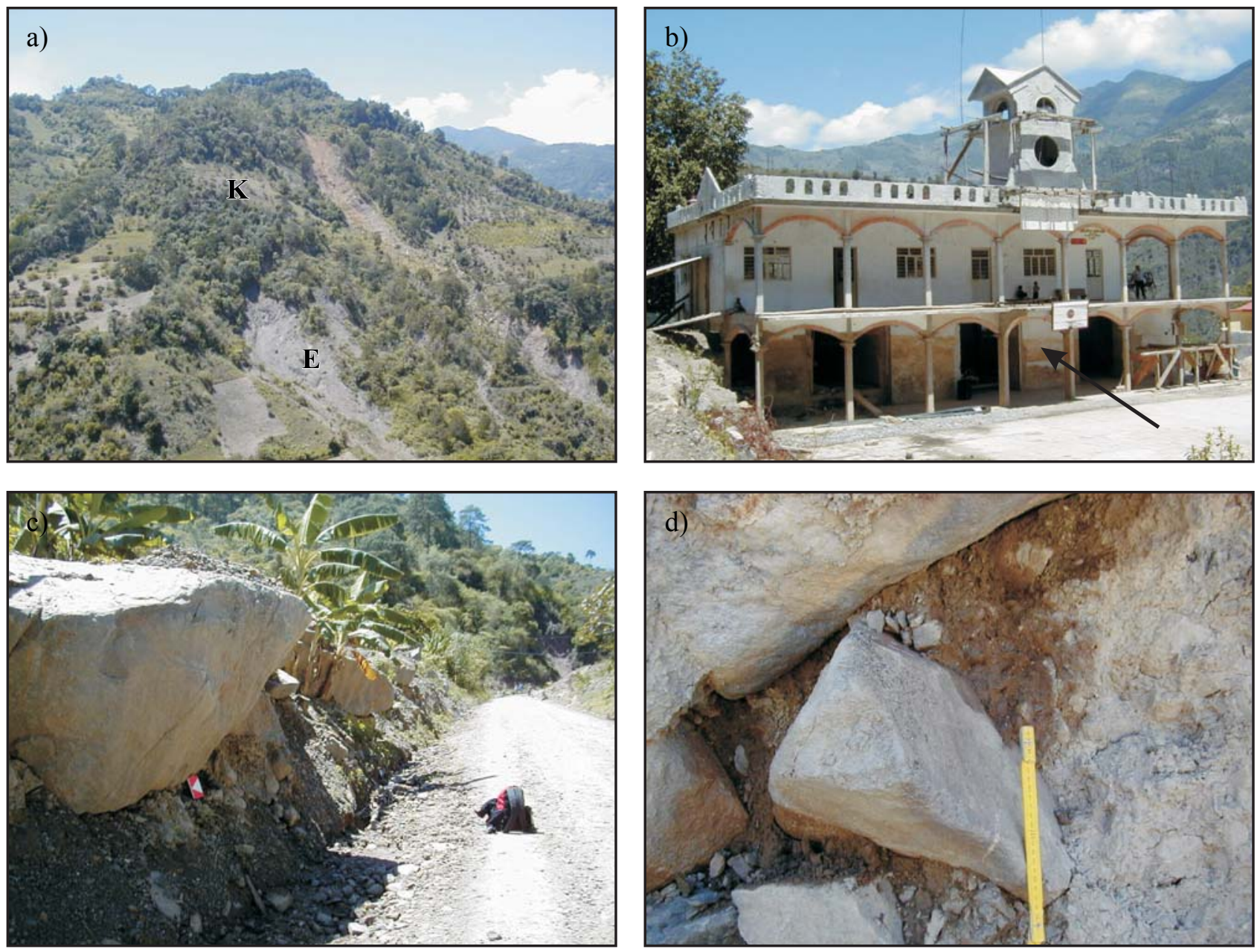

Figura 7. a) Panorámica del deslizamiento ocurrido en la ladera sur del poblado de Totomoxtla, en donde se aprecian los horizontes de calizas (K) sobreyaciendo a las filitas (F). b) Fotografía del municipio en donde se puede apreciar el límite de inundación del flujo (flecha negra). c) Fotografía del depósito de flujo de escombros con bloques de algunos metros de diámetro acumulados en la parte superior. d) Detalle del depósito con soporte granular entres los fragmentos más grandes embebidos en una matriz fina.

del flujo. Este comportamiento es típico de flujos cohesivos. El elevado porcentaje de arcilla le brinda al flujo una cohesión elevada lo cual impide que por simple gravedad los fragmentos líticos más grandes se hundan hacia la base. Adicionalmente, la matriz cohesiva reduce la fricción entre los bloques por lo cual no hay una disipación rápida de energía y el flujo puede moverse por grandes distancias sin transformarse en otro tipo de flujo. Por el contrario, los flujos no cohesivos se diluyen rápidamente en cortas distancias transformándose de flujos de escombros a flujos hiperconcentrados (con muy poco material en suspensión) (Scott, 1988).

\section{Conclusiones}

Con base en el estudio llevado a cabo se puede afirmar que el relieve que rodea el poblado de Totomoxtla es altamente susceptible a fenómenos de deslizamiento con formación de flujos de escombros cohesivos muy peligrosos. El evento ocurrido en 1999 fue disparado por lluvias abundantes, sin embargo las características de las rocas y su estructura particular determinó el tipo de flujo. Este es un ejemplo que se puede generalizar a la Sierra Norte de Puebla en donde predomina una estructura geológica plegada con alternancia de rocas de distinta competencia y reología. Estas condiciones indican la necesidad de un estudio geológico detallado como herramienta para poder obtener mapas de susceptibilidad para deslizamientos. Es claro que se trata de un fenómeno natural acelerado por la actividad antrópica. Las acciones preventivas para poder evitar desastres futuros en caso de deslizamientos de volúmenes grandes, se limitan entonces a la reubicación de algunas de las viviendas que se encuentren en las áreas más susceptibles. Poder controlar con obras civiles movimientos como los ocurridos en los poblados de Zapotitlán de Méndez o Totomoxtla no sería posible debido al volumen $\mathrm{y}$ dimensiones de las laderas inestables. 


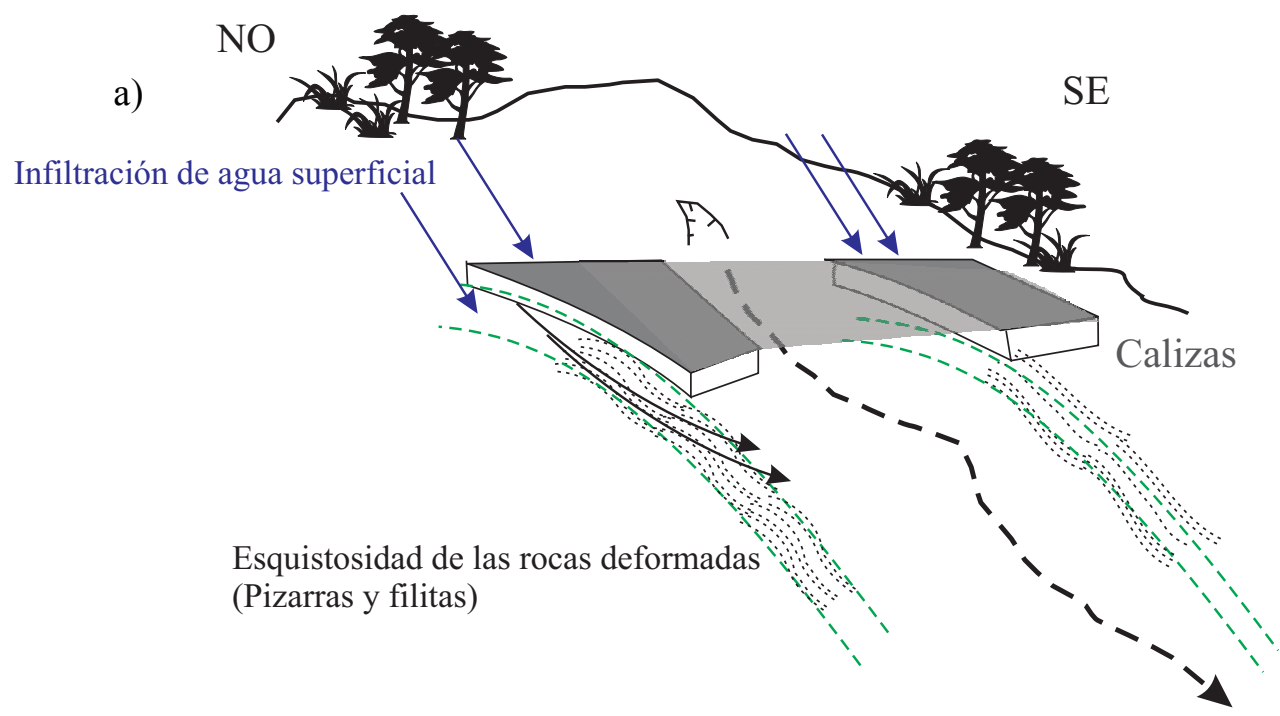

Trayectoria del flujo de escombros que se originó en 1999.

b)
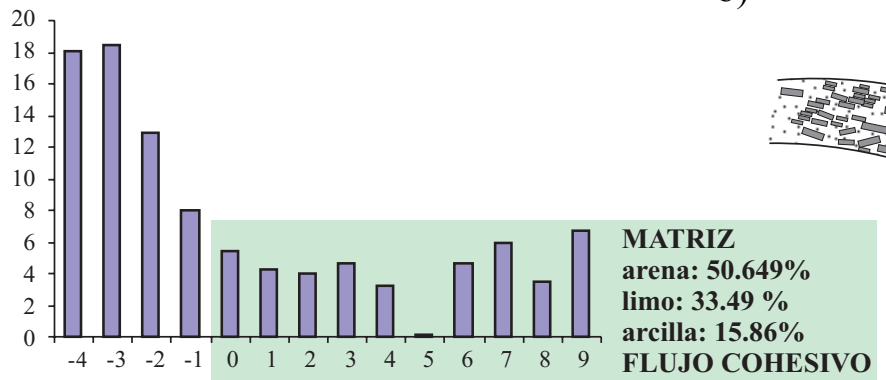

Figura 8. a) Esquema de la estructura geológica de la ladera afectada por el deslizamiento en el poblado de Totomoxtla. Aquí se resalta la presencia de horizontes compactos de calizas por encima de filitas y pizarras en las cuales se ha formado el plano de fallamiento. b) Estructura del flujo de escombros en donde se resalta la acumulación de los fragmentos de calizas en la parte superior del depósito e histograma granulométrico del depósito evidenciando la composición de la matriz que contiene un $15 \%$ de fracción arcillosa.

\section{Agradecimientos}

El presente trabajo ha sido financiado por el Instituto de Geografía y por el proyecto PAPIIT-DGPA IN110905 (a J.J. Zamorano-Orozco). Un agradecimiento especial a los Drs. José Luis Macías y Victor Hugo Garduño por sus invaluables sugerencias y al Dr. Armando García-Palomo como editor científico del volumen. Los autores quieren expresar su agradecimiento por el apoyo logístico brindado por Protección Civil del Estado de Puebla. Las imágenes de satélite fueron adquiridas en el sitio Global Land Cover Facility de forma gratuita (http://glcfapp.umiacs.umd. edu:8080/esdi/index.jsp).

\section{Referencias Bibliográficas}

Alcántara-Ayala, I., 2002. Geomorphology, natural hazards, vulnerability and prevention of natural disasters in developing countries. Geomophology, 47(2-4): 107-124.

Alcántara-Ayala, I., Esteban-Chávez, O. and Parrot, J.F., 2006.
Landsliding related to land-cover change: A diachronic analysis of hillslope instability distribution in the Sierra Norte, Puebla, Mexico. Catena, 65(5): 152-165.

Caballero, L., Macías, J.L., García-Palomo, A., Saucedo, R., Borselli, L., Sarocchi, D. and Sánchez, J.M., 2006. The September 8-9, 1998 Rain-Triggered Flood Events at Motozintla, Chiapas, Mexico. Natural Hazards, 39(1): 103-126.

Capra, L., Lugo-Hubp, J. and Borselli, L., 2003a. Mass movements in tropical volcanic terrains: the case of Teziutlán (México). Engineering Geology, 69: 359-379.

Capra, L., Lugo-Hubp, J. and Dávila-Hernandez, N., 2003b. Fenómenos de remoción en masa en el poblado de Zapotitlán de Méndez, Puebla: relación en tre litología y tipo de movimiento. Revista Mexicana de Ciencias Geológicas, 20(2): 95-106.

Hoek, E., Marinos, P., Benissi, M., 1998. Applicability of the geological strength index (GSI) classification for very weak and sheared rock masses. The case of the Athens Aschist Formation. Bulletin of Engineering Geology and the Environment, 57 (2): 151-160.

Instituto Nacional de Estadística Geografía e Informática (INEGI), 1984. Carta geologica Veracruz, F14-3, escala 1: 250,000: Mexico. Instituto Nacional de Estadística, Geografía e Informática.

López-Reyes, J.J., de los Santos, S., Cacho, S. and Sánchez -Bermeo, G., 1997. Carta geológico minera Pachuca, F14-11, escala 1:250,000. Consejo de Recursos Minerales.

Lugo-Hubp, J., Zamorano, J.J., Capra, L., Inbar, M. and Alcántara-Ayala, 
I., 2005. Los procesos de remoción en masa en la Sierra Norte de Puebla, octubre de 1999, causas y efectos. Revista Mexicana de Ciencias Geológicas, 22(2): 212-228.

Lugo-Hubp, J., Vazquez-Conde, M.T., Melgarejo-Palafox, G., GacíaJimenez, F. and Matias-Ramirez, G., 2001. Procesos gravitacionales en las montañas de Puebla. Ciencias y desarrollo, 27(157): 24-33.

Scott, K. M., 1988. Origins, behavior, and sedimentology of lahars and lahar-runout flows in the Toutle-Cowlitz River system. U.S. Geological Survey Professional Paper, 1447-A, 74 pp.
Vazquez-Conde, M.T., Lugo-Hupb, J. and Matías, L.G., 2001. Heavy rainfall effects in Mexico during early october 1999. In: E. Gruntfest and J. Handmer (Editors), Coping with flash floods. Kluwer Academic Press, Nethwelands, pp. 289-299.

Manuscrito recibido: Octubre 12, 2006

Manuscrito corregido recibido: Enero 10, 2007

Manuscrito aceptado: Febrero 1, 2007 